\title{
OS MODOS INFINITOS E FINITOS NA ÉTICA DE BENEDICTUS SPINOZA
}

\section{Emanuel Angelo da Rocha Fragoso}

Doutorando em Filosofia - UFRJ, Mestre em Filosofia - UFRJ, Professor de Filosofia

A teoria spinozista dos modos se reveste de uma particular dificuldade: o fato de Spinoza não a ter exposto com suficiente desenvolvimento para sua perfeita compreensão. Os modos na ÉTICA de Spinoza são definidos como afecções da substância. Esta caracterização os torna dependentes ontológicos dessa mesma substância, determinando-os como a sua contrapartida lógica: se a substância existe em si e é concebida por si, os modos são concebidos por aquilo em que existem e não por si próprios. As definições de substância e modo estabelecem uma relação de dependência ontológica, simétrica e oposta entre a substância e os modos.

Palavras-chave: Spinoza - Ética - Deus - Substância - Modos - Infinito - Finito

\section{Os Modos}

Por modo entendo as afecções da substância, isto é, o que existe noutra coisa pela qual é também concebido (ÉTICA, Livro 1, Definição 5).

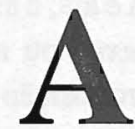
o definir a categoria ontológica dos modos como afecções da substância, Spinoza caracteriza-os como dependentes ontológicos da substância. Esta caracterização pode ser melhor evidenciada quando comparamos a substância com os modos e observamos que eles são determinados como a contrapartida lógica da substância: se a substância existe em si (in sui), os modos existem em outra coisa (in alio); se a substância é concebida por si, os modos são concebidos por aquilo em que existem e não por si próprios; ou seja, as definições de substância e modo estabelecem uma relação de dependência ontológica, simétrica e oposta entre a substância e os modos. A nosso ver, ainda que controversa e não autorizada por Spinoza (DELBOS, 1987, p.54), a interpretação mais correta para a relação de dependência ontológica entre a substância e os modos é a de que o spinozismo estabelece entre estas duas categorias do real uma hierarquia ontológica que tem a substância (por ser infinita absolutamente) como ápice e os modos (por não participarem desta infinitude absoluta e parte deles serem finitos) como termo; aos atributos fica reservada uma posição intermediária, já que eles são infinitos apenas em seu gênero.
A teoria spinozista dos modos se revela com particular dificuldade, visto Spinoza não a ter exposto com suficiente desenvolvimento para sua perfeita compreensão. Devido a sua importância para o sistema spinozista, apesar de controversa, a análise da teoria dos modos em Spinoza se faz necessária. Entretanto, por não concordarmos e nem discordarmos na totalidade com nenhuma das interpretações que foram escritas pelos diversos comentadores, limitaremos nossa análise à explicitação e exposição mais completa possível do conjunto de interpretações estudadas.

Em sua totalidade a teoria dos modos em Spinoza abrange tudo aquilo que não é concebido por si; ou seja, todas as coisas que não podem existir nem serem concebidas sem Deus. Pois se na natureza nada existe de contingente, tudo é determinado pela necessidade da natureza divina a existir e a operar de modo certo (ÉTICA, livro I, Proposição 29), tudo o que existe, ou existe necessariamente devido à sua essência e definição ou existe necessariamente de uma dada causa eficiente (ÉTICA, Livro I, Proposição 33, Escólio 1). Portanto, a teoria dos modos deve compreender tudo aquilo que existe necessariamente de uma dada causa eficiente, já que o que existe por sua essência e definição são 
o próprio Deus (causa sui) e seus atributos. Esta teoria compreende o modo infinito imediato, o modo infinito mediato e os modos finitos, ou as coisas particulares.

Os modos infinitos imediatos são os que resultam necessariamente da natureza absoluta de Deus (ÉTICA, Livro I, Proposição 21, Demonstração) ou que resultam da natureza absoluta de qualquer atributo de Deus (ÉTICA, Livro I, Proposição 21); ou seja, são os modos que resultam imediatamente de Deus ou de qualquer atributo de Deus sem o concurso de outras circunstâncias. Estes modos são eternos (são sempre os mesmos desde toda a eternidade) e infinitos pela sua causa eficiente, dada a impossibilidade de se demonstrar o contrário, visto eles serem causados pela substância absolutamente infinita ou por atributos infinitos em seu gênero considerados absolutamente. Assinale-se aqui que o sentido dado por Spinoza à "existência eterna" destes modos é o da coisa ter existido sempre (ÉTICA, Livro I, Proposição 21); ou seja, nesta proposição a "eternidade" está sendo relacionada com o tempo; trata-se mais especificamente de uma existência sem começo e nem fim do que de uma "eternidade" propriamente dita. Neste sentido dado, a "existência eterna" aqui referida é justamente a duração, pois Spinoza define esta como a continuação indefinida da existência (ÉTICA, Livro II, Definição 5). Por conseguinte, os modos infinitos imediatos são ditos eternos em um sentido diferente daquele que é dito da coisa que é eterna em virtude de sua essência ou definição como coisa eterna. Nestas últimas, a eternidade é um tipo específico da existência que não tem nenhuma relação com a duração e o tempo. Segundo a Carta LXIV, a Schuller (SPINOZA, 1964, v. 4 , p. 315), o modo infinito imediato para o atributo pensamento é o intelecto absolutamente infinito; para o atributo extensão é o movimento e repouso.

Os modos infinitos mediatos são os que resultam de qualquer atributo de Deus, enquanto é afetado por uma modificação que, em virtude do mesmo atributo, existe necessariamente e é infinita (ÉTICA, Livro I, Proposição 22); ou seja, são os modos que resultam de um atributo de Deus enquanto é afetado por um modo infinito imediato. São infinitos e existem necessariamente em virtude de resultarem de algum atributo divino infinito em seu gênero, mediante alguma modificação que resulta imediatamente da natureza absoluta do mesmo atributo que exista necessariamente e seja infinita (ÉTICA, Livro I, Proposição 23, Demonstração). Ainda segundo a Carta LXIV, a Schuller, para o atributo extensão ele é a figura ou fisionomia do universo no seu conjunto, a qual se mantém sempre a mesma a despeito de ele variar em modos infinitos [facies totius universi]. Para o atributo pensamento, Spinoza não deixou exemplos; porém, Delbos aventa a hipótese de ser a ordem total das almas eternas, aquela ordem onde elas constituem uma unidade anterior a suas determinações singulares, que forma no pensamento o modo infinito e eterno mediato, simétrico da facies totius universi (1987, p. 61).

Para Deleuze, o modo infinito mediato do atributo pensamento é o conjunto das relações ideais que regulam as determinações das idéias como idéias de modos existentes; para o atributo extensão, é a facies totius universi, que significa o conjunto de todas as relações de movimento e repouso que regulam as determinações dos modos enquanto existentes (1970, p. $101 \mathrm{e} 102$ ).

Os modos finitos são afeç̧ões dos atributos de Deus ou modos pelos quais os atributos de Deus se exprimem de maneira certa e determinada (ÉTICA, Livro I, Proposição 25 , Corolário); isto é, o modo finito são as coisas singulares que percebemos no tempo e no espaço com existência empírica, finita e determinada (ÉTICA, Livro I, Proposição 28). São idênticos às coisas singulares e têm como característica possuírem uma essência que não envolve a existência; ou seja, a sua existência, a sua ação e o próprio encaminhamento destas não têm origem em sua essência. Porque não possuem a existência necessária, as coisas singulares ou toda coisa que é finita e tem uma existência determinada não pode existir e nem ser determinada a agir se não é determinada a existir e a agir por outra causa além delas mesmas. Esta causa é também finita e tem existência determinada por outra causa além dela mesma; e esta outra causa por sua vez, também possui uma causa finita com existência determinada que faz com que exista e aja; e assim indefinidamente. É a infinitus causarum nexus ou nexo infinito de causas [finitas] (ÉTICA, Livro V, Proposição 6).

A demonstração de Spinoza dada na proposição XXVIII, do Livro I da ÉTICA, intenta provar que os modos finitos são determinados a existir e a agir por Deus enquanto é afetado por uma modificação que é finita e tem existência determinada. Sendo as coisas particulares finitas e com o agir determinado, sua causa eficiente não poderia ser a natureza absoluta de Deus ou a natureza absoluta de algum atributo seu, pois o que resulta imediatamente da natureza absoluta de Deus ou de um atributo divino é eterno e infinito. Todavia, Deus é a causa eficiente de todas as coisas que existem (ÉTICA, Livro I, Proposição 25) e tudo o que existe, existe em Deus (ÉTICA, Livro I, Proposição 15); logo, os modos finitos só podem ter como causa eficiente Deus ou algum atributo seu. A solução spinozista baseia-se na distinção da causalidade divina em causa imediata sem o concurso de outras circunstâncias e causa mediata, com o concurso de outra coisa além da ação divina: na primeira Deus é causa imediata, as coisas resultam necessariamente de sua natureza absoluta ou da natureza absoluta de algum 
atributo seu independentemente de todas as outras circunstâncias (como vimos no caso dos modos infinitos imediatos); na segunda Deus é a causa mediata, as coisas resultam de algum atributo divino não considerado absolutamente e sim com o concurso ou influência de outras coisas (como vimos no caso dos modos infinitos mediatos). Ressalte-se aqui que estas "outras coisas" não podem agir sem Deus ou fora dele, porque Deus age somente segundo as leis de sua natureza, sem ser constrangido por ninguém (ÉTICA, Livro I, Proposição 17). Portanto, Deus determina a ser e mantém a existência das coisas particulares não por sua natureza considerada absolutamente, mas por sua natureza afetada desta ou daquela modificação (DELBOS, 1987, p.62).

Entretanto, os modos finitos têm uma existência empírica ou uma duração que é uma sucessão de fenômenos, e uma existência eterna de uma essência singular onde se exprime de forma determinada o poder infinito que se manifesta nos atributos divinos (MOREAU, 1982, p. 40). Donde podemos concluir que aqui a causalidade divina se manifesta de duas maneiras distintas que correspondem aos dois efeitos: a existência eterna das essências singulares e a existência na duração destas mesmas essências. Vejamos mais detidamente a existência e a essência dos modos finitos.

No escólio da proposição XXIX do Livro V da ÉTICA, Spinoza cita os dois modos em que as coisas por nós concebidas têm existência atual:

As coisas são concebidas por nós, como atuais, de dois modos: ou enquanto concebemos que elas existem com relação a um tempo e a um lugar determinados, ou enquanto concebemos que elas estão contidas em Deus e que resultam da necessidade da natureza divina. Ora, as que são concebidas como verdadeiras, ou seja, reais, deste segundo modo, concebemo-las do ponto de vista da eternidade, e as idéias delas envolvem a essência eterna $e$ infinita de Deus,...[grifo nosso]

Delbos analisa as coisas singulares sob a ótica do escólio acima citado e interpreta-as como tendo uma dupla existência: por um lado, a existência que se define por uma relação a um lugar e a um momento determinado (existência empírica); por outro lado, a existência que se define por uma relação à causalidade imanente de Deus e que resulta da necessidade da natureza divina (existência eterna singular); ou seja, as coisas singulares existem porque são determinadas a ser pelo conjunto das outras coisas existentes a exercer $\mathrm{em}$ um certo momento a força que elas têm de suas essências e porque têm uma essência eterna advinda da substância absolutamente infinita (DELBOS, 1987, p. 65 e 66).

As coisas singulares certamente podem ser por nós concebidas como existindo atualmente do primeiro modo, pois elas têm existência determinada (ÉTICA, Livro I, Proposição 25, Corolário); quanto ao segundo modo, se afora Deus nada pode ser concebido (ÉTICA, Livro I, Proposição 14) e as coisas particulares são definidas como afecções dos atributos de Deus (ÉTICA, Livro I, Proposição 25, Corolário), também nos é lícito concebê-las como existindo atualmente deste modo. No primeiro modo, estamos concebendo a existência dos modos finitos na duração como realidade física; no segundo modo, estamos concebendo a existência da essência singular dos modos finitos como existindo em ato ou como realidade física. Portanto, as essências das coisas singulares também são realidades físicas que têm uma existência atual. Contudo, a existência eterna das essências singulares dos modos finitos não deve ser confundida com a existência na duração destas mesmas essências e nem tampouco devemos identificar os modos finitos com a substância única e eterna, visto aqueles terem essências eternas.

Quanto à distinção entre a existência eterna das essências singulares dos modos finitos e a existência na duração destas mesmas essências cabe novamente ressaltar a concepção spinozista de eternidade: é uma existência que não tem nenhuma relação com a duração (continuação indefinida do existir) e nem com o tempo. Neste sentido, a existência eterna das essências singulares deve ser concebida como seqüência de sua essência mesma ou definição como coisa eterna (ÉTICA, Livro I, Definição 1), elas devem necessariamente ter a sua existência implícita em si mesmas. Ora, Deus é a causa que produz todas as coisas (ÉTICA, Livro I, Proposição 18) e à essência das coisas produzidas por ele não pertence o existir (ÉTICA, Livro I, Proposição 24, Corolário); portanto, a essência dos modos finitos e infinitos não implica a sua existência; Deus é a causa de suas existências e de suas essências (ÉTICA, Livro I, Proposição 25). Logo, a existência eterna e a existência na duração das essências singulares devem ser compreendidas em Deus, mas com sentidos distintos entre si. A existência eterna das essências singulares resulta de maneira incondicional dos atributos divinos; enquanto a existência destas mesmas essências na duração é condicionada pelo nexo infinito de causas finitas. A existência de cada essência singular na duração depende da existência anterior de uma série indefinida de outras existências singulares na duração. Segundo Delbos: a ordem comum da natureza, onde as coisas particulares encontram sua existência e seu gênero próprio de ação, é o nexo infinito das causas [finitas], infinitus causarum nexus (DELBOS, 1987, p. 62).

Quanto à identificação dos modos finitos com a substância única, vimos anteriormente que Deus é a causa eficiente das coisas particulares, pois Deus é a causa eficiente de todas as coisas (ÉTICA, Livro I, Proposição 25); contudo, como ele é substância única, todas as coisas produzidas por ele estão nele porque ele é causa imanente [que produz 
efeitos em si mesmo] de todas as coisas e não [causa] transitiva [produz efeitos fora de si] (ÉTICA, Livro I, Proposição 18). Entretanto, isto não nos autoriza identificar Deus com os modos finitos porque eles são definidos como as coisas particulares pelas quais os atributos divinos se exprimem sob uma forma determinada (ÉTICA, Livro I, Proposição 25, Corolário) cuja essência não envolve a existência (ÉTICA, Livro I, Proposição 24); ou seja, as coisas singulares não têm aquela existência necessária, infinita , absoluta que se chama eternidade; tem apenas uma existência limitada a que se pode chamar duração (MOREAU, 1982, p. 37). Segundo o próprio Spinoza em carta a Louis Meyer:

se atendemos somente à essência dos modos, e não à ordem de toda a natureza, não podemos concluir da sua existência presente à sua existência ou não existência futura nem à sua existência ou não existência passada. Donde se deduz claramente que a existência da substância é concebida como totalmente diferente da existência dos modos [grifo nosso] (SPINOZA, 1964, v. 4, p. 156).

Assim, os corpos são apenas determinações particulares do atributo infinito extensão e os entendimentos finitos são apenas modos do atributo infinito pensamento que não podem ser identificados com a substância absolutamente infinita ou Deus.

\section{REFERÊNCIAS BIBLIOGRÁFICAS}

DELBOS, Victor. Le Spinozisme. 5. ed. Paris: J. Vrin, 1987. 215 p. (Bibliotéque D'Histoire de la Philosophie).

DELEUZE, Gilles. Espinosa e os Signos. Tradução por Abílio Ferreira. Porto: Rés, 1970. 205 p. (Colecção Substância). Tradução de: Spinoza.

MOREAU, Joseph. Espinosa e o Espinosismo. Tradução por Lurdes Jacob e Jorge Ramalho. Lisboa: Edições 70, 1982. 110 p. (Biblioteca Básica de Filosofia, 20). Tradução de: Spinoza et le spinozisme.

SPINOZA, Benoit de.Espinosa. Seleção de textos de Marilena Chauí; traduções por Marilena Chauí et al. 3. ed. São Paulo: Abril Cultural, 1983. 394 p. (Os Pensadores).
Éthique. Texto introdutório e tradução por Charles Appuhn. Paris: J. Vrin, 1983.2 v. em 1. (Bibliotéque des Textes Philosophiques). Tradução de: Ethica.

Cuvres. Tradução, notícias e notas por Charles Appuhn. Paris, GF Flamarion, 1964. 4 v. 